\title{
Observable and Unobservable Involvement Behaviours of a Climatology Course's Undergraduate Students
}

\author{
T. M. Seixas* and M. A. Salgueiro da silva
}

Department of Physics and Astronomy, Faculty of Science, University of Porto, Rua do Campo Alegre, Porto, Portugal and Centre for Earth and Space Research of the University of Coimbra (CITEUC), Coimbra, Portugal

\begin{tabular}{|c|c|}
\hline ARTICLE INFO & ABSTRACT \\
\hline $\begin{array}{l}\text { Keywords: } \\
\text { Classroom Involvement } \\
\text { Behaviours } \\
\text { Scaffolding Collaborative } \\
\text { Problem-Solving } \\
\text { Observable and } \\
\text { Unobservable Attitudes } \\
\text { Cronbach Alpha } \\
\text { Coefficient }\end{array}$ & $\begin{array}{l}\text { This study investigated students' observable and unobservable } \\
\text { involvement behaviours and their possible relation with academic } \\
\text { achievement in a Climatology course at the Department of Physics } \\
\text { and Astronomy of the Faculty of Sciences of the University of Porto, } \\
\text { Portugal, in the Fall 2018/19. A structured online questionnaire titled } \\
\text { "Observable and Unobservable Student Involvement Behaviours } \\
\text { (OUSIB)" featuring a zero-centred 5-point Likert scale was used to } \\
\text { collect the data. The OUSIB questionnaire comprised } 20 \text { multiple- } \\
\text { choice questions, which were divided into two subscales: (1) } \\
\text { Observable Involvement Behaviours; (2) Unobservable Involvement } \\
\text { Behaviours; it was validated using Cronbach coefficient alpha. The } \\
\text { collected data show that unobservable involvement behaviours are } \\
\text { more frequent than the observable ones. This may reflect the } \\
\text { difficulties that most students face in understanding the course } \\
\text { contents, which likely triggers their introspective (unobservable) in } \\
\text { detriment of their observable involvement behaviour. We notice that } \\
\text { most of the Climatology syllabus consists of new subjects for which } \\
\text { students generally have no prior knowledge or experience. It may } \\
\text { constitute a great challenge for students being able to provide regular } \\
\text { observable feedback during an entire problem-solving class. } \\
\text { Moreover, there is a common tendency for high-grade students to } \\
\text { prepare the classes in advance and involve less both observably and } \\
\text { unobservably in classroom activities. We found no significant } \\
\text { correlation between students' final grades and their replies to the } \\
\text { OUSIB questionnaire, which precludes any possible relationship } \\
\text { between students' academic achievement and their involvement } \\
\text { behaviours in problem-solving classes. }\end{array}$ \\
\hline
\end{tabular}

\section{Introduction}

Different authors have argued (Trilling et al., 2009; Bereiter, 2002; National Research Council, 2000) that the development of higher order competencies in $21^{\text {st }}$ century students such as metacognition, cooperation, creativity and agency are crucial to their successful learning experience. According to Yang et al. (2019) all students need equitable access to these competencies, regardless their academic background or socioeconomic status. In particular, successful learning experiences that focus on higher-order competencies are critically important among low achievement students. Higher-order competencies not only help academic performance, narrowing the achievement gap, but also create a cycle of continuous improvement (Snell et al., 2018; Becker et al., 2002). Recently, the published report How 
People Learn II (National Academy of Science, Engineering and Medicine, 2018) emphasized that addressing the needs of all learners is still an area of substantial research.

Collaborative instructional approaches that emphasize higher-order competencies have many benefits for learners, such as deep understanding, critical thinking, and self-efficacy (Chan, 2013). In collaborative physics problem-solving processes, students construct a physical model of the problem task using their previous knowledge, learned on lectures and solve it in interaction with each other and the instructor on seminar classes. Problem solving is a central method of instruction in physics. A similar central instructional methodology has been reported in mathematics education by Torner et al. (2007), due to its importance in today's increasingly interconnected world (OECD, 2017). According to the Finnish national curriculum, learning together stimulates curiosity and interest and promotes students' creative and critical thinking and problem-solving skills, as well as their ability to understand different perspectives and phenomena (FNBE, 2014). While solving problems, students argue, reason, and make conclusions and new inventions about course contents (Haataja et al., 2019).

The role of instructors in collaborative problem-solving processes is mainly to assess and guide students as they work (Stein et al., 2008). Studies carried out by Haataja et al. (2019), Rosales et al. (2012), and Polya, (1957) pointed out the important role of instructors in helping students to generalize their solutions to build a more abstract understanding of the situation. Haataja (2019) conducted a review of the literature on scaffolding collaborative problem solving and reported that Wood, Bruner, and Ross (1976) were the first to define scaffolding as the instructor's guiding role in students' problem-solving learning process in order to help them to achieve the learning goals in their Zone of Proximal Development - ZPD (Vygotsky, 1978). A sufficient amount of proper scaffolding directs students' attention towards reaching the learning objectives (Frith \& Frith, 2012; Schnotz, 2010). According to Kirschner et al. (2006) and a number of reviews of empirical studies conducted from 1950 to 1980s (Mayer, 2004) they support direct, strong instructional guidance rather than constructivist-based minimal guidance during the instruction of novice to intermediate learners. Unguided instructional is usually less effective even for high-achieving students with considerable prior knowledge, where it is most often found to be equally effective as unguided approach. There is also evidence that lowachieving students develop higher order competencies with guided instruction (Yang, 2019). Qualitative studies carried out by Aulls (2002) describe scaffolding as the most effective instructional methodology introduced by teachers when their students failed to make learning progress. He also reported that when students acquire misconceptions or incomplete or disorganized knowledge scaffolding relevant procedures are the most efficient to correct them. According to Van de Pol et al. (2010), scaffolding is a dependent interactive process between the instructor and students. The instructor' role in scaffolding students' problem-solving process becomes gradually less strong as students' actions and competence increase. Despite the successful teaching strategy of cooperative learning in which small teams, each with students of different levels of ability, use a variety of learning activities to improve their understanding of a subject (Slavin, 1996), the right balance of guidance and autonomy is individual as students have different kinds of needs (Haataja et al., 2019). High-achieving students show normally more active involvement behaviour in learning activities than lowachieving students. A variety of factors might influence students' involvement in learning activities. Research findings indicate that optimal learning takes place when learning activities are meaningful, enjoyable, interesting, and challenging (Bransdford et al., 1990, Deci et al., 1992). According to Astin (1984) and reported by Sak et al. (2012) involvement can be defined as the amount of physical and psychological energy students devote to experience. For instance, ideas, dreams, glandular responses, running, reading in silent etc are actions that are not overtly observed, yet, they hold significant value influencing the overt behaviours (Shrestha, 2017). Sak (2012) also argued that these behaviours can be implicit or explicit. Even though students 
engage in learning activities at a maximum level, their involvement behaviours can sometimes be observable and unobservable in other occasions. As reported by Sak (2012) involvement behaviours in learning activities might be of two types, overt behaviours and covert behaviours. Overt behaviours are observable, including asking questions, raising hands, answering questions, verbally criticizing ideas, writing thoughts, undertaking classroom assignments, and participating in group discussions. Covert behaviours can be defined as unobservable ones, such as thinking about problems, making connections and questioning issues in mind. As reported by empirical studies of Eggen et al. (2003) and Ellis et al. (1994) the level of active involvement in learning activities could be one of the best predictors of level of learning and of academic achievement.

\section{Research Methodology}

\subsection{Population}

The population in this study was 36 sophomore students from Climatology subject (Fig. 1) who studied in degree in Environmental Sciences and Technology at the Faculty of Sciences of the University of Porto, in Portugal, during the 2018/19 academic year. The participants were distributed almost evenly by gender, with $46 \%$ of females and $54 \%$ of males. The present work investigated involvement behaviours in problem-solving classes, where a guided cooperative instructional methodology was applied.

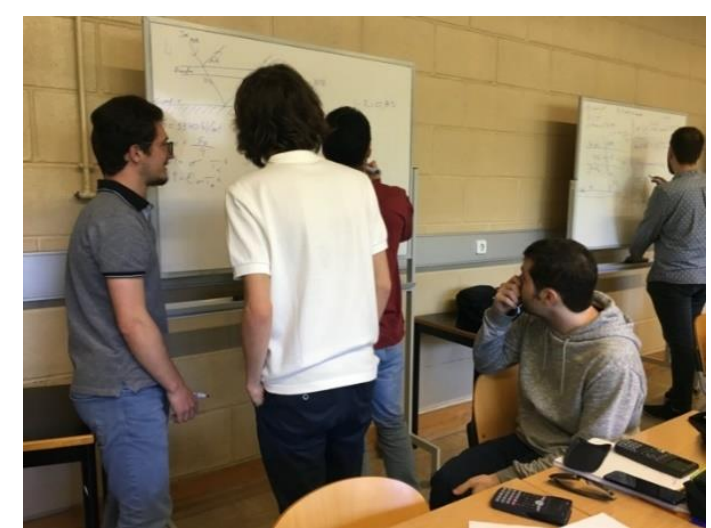

Figure 1. Students of Climatology at cooperative seminar classes (Source: credit: Climatology instructor (2018/19-FCUP))

\subsection{Research procedure and instrument}

The research instrument used in this study was an online questionnaire titled "Observable and Unobservable Student Involvement Behaviours (OUSIB)", originally designed and tested by Sak et al. (2012). It comprises 20 multiple-choice questions (see Tab. 1), which were divided into two subscales: (1) Observable Involvement Behaviours; (2) Unobservable Involvement Behaviours. The questionnaire has a five-point Likert scale with the format: strongly disagree (SD), disagree (D), undecided (U), agree (A) and strongly agree (SA). In order to obtain a zerocentred scale, the responses SA, A, U, D and SD were respectively assigned values of $+2,+1$, $0,-1,-2$. 
Table 1.

OUSIB questionnaire (Sak et al., 2012)

\begin{tabular}{clc}
\hline Item & Question & Subscale \\
\hline 1 & I ask questions to the teacher about topics s/he teaches. & 1 \\
2 & I take notes about topics the teacher teaches. & 1 \\
3 & I verbally answer questions. & 1 \\
4 & I express my own ideas about topics being discussed. & 1 \\
5 & I ask the teacher for elaborations and clarifications about topics I do not & 1 \\
6 & understand well. & 1 \\
7 & I give examples about topics under discussion. & 1 \\
8 & I ask the teacher to give examples while s/he is teaching. & 1 \\
9 & I actively participate in group studies. & 1 \\
10 & I initiate discussions about current issues, trends or news related to topics of the & 1 \\
& day. & \\
11 & I put the last touches on topics and discussions of the day in the class that I think & 1 \\
12 & are incomplete. & 2 \\
13 & I carefully listen to the teacher. & 2 \\
14 & I try to make connections between what is talked and what we learn before. \\
15 & I think and question in my mind about reasons and effects of issues being & 2 \\
16 & discussed. & 2 \\
17 & I try to understand learning activities of the lesson. & 2 \\
18 & I pay attention to the teacher's gestures and mimics. & 2 \\
19 & I try to find examples from real life about topics being discussed in the lesson. \\
20 & I try to understand the importance of topics in the life of living things. & 2 \\
\hline & & 2 \\
\hline
\end{tabular}

The online OUSIB questionnaire was distributed to students using Moodle platform at the University of Porto at the end of the academic semester.

\section{Data Analysis}

The data of the OUSIB survey were grouped and analysed using Excel. The mean and sample standard deviation (STD) were calculated for each item. Percentages of disagreement, undecided and agreement were also calculated. The percentage of agreement was determined by adding the percentages of SA and A. The percentage of disagreement was obtained by adding the percentages of SD and D. Mean, standard deviation (STD) and percentages for the two subscales were also calculated. To validate the OUSIB questionnaire, we calculated the Cronbach alpha for both subscales. We also calculated the correlation between students' responses to the OUSIB questionnaire and their final grades, to assess any possible relationship between their involvement behaviour in learning activities and academic achievement.

\section{Research Findings}

Table 2 shows the mean, standard deviation (STD) and percentages of agreement, undecided and disagreement for the overall sample of OUSIB questionnaire.

Table 2.

Mean, standard deviation and percentages for the overall sample of OUSIB questionnaire

\begin{tabular}{ccccccc}
\hline Item & Subscale & MEAN & STD & A+SA \% & U \% & D+SD \% \\
\hline 1 & 1 & 1,08 & 0,49 & 92,3 & 7,7 & 0,0 \\
2 & 1 & 1,62 & 0,65 & 92,3 & 7,7 & 0,0 \\
3 & 1 & 0,92 & 0,64 & 76,9 & 23,1 & 0,0 \\
4 & 1 & 0,69 & 0,95 & 53,8 & 38,5 & 7,7 \\
5 & 1 & 1,15 & 0,69 & 84,6 & 15,4 & 0,0 \\
6 & 1 & 0,23 & 1,09 & 46,2 & 30,8 & 23,1
\end{tabular}




\begin{tabular}{ccccccc}
7 & 1 & 1,00 & 0,58 & 84,6 & 15,4 & 0,0 \\
8 & 1 & 0,38 & 0,77 & 38,5 & 53,8 & 7,7 \\
9 & 1 & 1,38 & 0,96 & 69,2 & 30,8 & 0,0 \\
10 & 1 & 0,38 & 1,04 & 46,2 & 30,8 & 23,1 \\
11 & 1 & 0,15 & 0,80 & 23,1 & 61,5 & 15,4 \\
12 & 2 & 0,92 & 0,86 & 76,9 & 15,4 & 7,7 \\
13 & 2 & 1,38 & 0,77 & 84,6 & 15,4 & 0,0 \\
14 & 2 & 1,31 & 0,63 & 92,3 & 7,7 & 0,0 \\
15 & 2 & 1,08 & 0,76 & 76,9 & 23,1 & 0,0 \\
16 & 2 & 1,46 & 0,52 & 100,0 & 0,0 & 0,0 \\
17 & 2 & 1,31 & 0,63 & 92,3 & 7,7 & 0,0 \\
18 & 2 & 0,85 & 0,69 & 69,2 & 30,8 & 0,0 \\
19 & 2 & 0,46 & 1,27 & 61,5 & 23,1 & 15,4 \\
20 & 2 & 0,85 & 0,90 & 53,8 & 46,2 & 0,0 \\
\hline
\end{tabular}

Data from subscale 1 (Observable Involvement Behaviours) shown in Table 2, indicate that the highest percentage of agreement was $92.3 \%$ for items 1-2 and the lowest percentage of agreement was $23.1 \%$ for item 11 , which has the maximum percentage of undecided $(61.5 \%)$. This seems to indicate that most students routinely ask questions to the teacher and take notes about topics s/he teaches, but do not clearly value contributing with the last touches to classroom discussions.

Percentages of agreement for subscale 2 (Unobservable Involvement Behaviours) have a minimum of $53.8 \%$ for item 20 and a maximum of $100 \%$ for item 16 . The percentages of disagreement are $0.0 \%$, except for item $19(15.4 \%)$. This suggests that students' unobservable involvement behaviours are quite common.

The obtained Cronbach's alphas were 0.85 for subscale 1 and 0.81 for subscale 2 (see Tab. 3). We note that a Cronbach alpha of 0.70 is generally considered acceptable for a reliable scale. The data show no evidence for a possible relationship between students' responses and their final grades, as can be inferred from the low correlations (GRADE CORR) of -0.12 and -0.09 obtained for subscales 1 and 2, respectively.

Table 3.

Mean, standard deviation, Cronbach alpha and correlation with final grades for both subscales of OUSIB questionnaire

\begin{tabular}{cccccc}
\hline & Subscale & MEAN & STD & ALPHA & GRADE CORR \\
\hline 1 & Observable Involvement Behaviours & 0,82 & 0,79 & 0,85 & $-0,12$ \\
2 & Unobservable Involvement Behaviours & 1,07 & 0,78 & 0,81 & $-0,09$ \\
\hline
\end{tabular}

\section{Discussion and Conclusion}

This study aimed at studying students' observable and unobservable involvement behaviours in learning activities of problem-solving classes of Climatology course and at assessing any possible relationship with students' academic achievement. The collected data show that unobservable involvement behaviours are more frequent than the observable ones. This may reflect the difficulties that most students face in understanding the course contents, which likely triggers their introspective (unobservable) in detriment of their observable involvement behaviour.

We notice that most of the Climatology syllabus consists of new subjects for which students generally have no prior knowledge or experience. It may constitute a great challenge for students being able to provide regular observable feedback during an entire problem-solving class. Moreover, there is a common tendency for high-grade students to prepare the classes in advance and involve less both observably and unobservably in classroom activities. Therefore, it is no surprise that we found no significant correlation between students' final grades and their replies for both subscales of the OUSIB questionnaire. 
In the sequence of this work, we plan to extend the study of observable and unobservable involvement behaviours to students from other courses.

\section{Acknowledgment}

Authors would like to thank FCUP's participant students for their contribution in the data collection. This work was carried out under project UID/Multi/00611/2019, funded by FCT/MEC (PIDDAC) and FEDER - European Regional Development Fund through COMPETE 2020 - Operational Programme Competitiveness and Internationalization (project: POCI-01-0145-FEDER-006922).

\section{References}

Astin, A.W. (1984). Student involvement: A developmental theory for higher education. Journal of College Student Personnel, 25, 297-308.

Aulls, M. W. (2002). The contributions of co-occurring forms of classroom discourse and academic activities to curriculum events and instruction. Journal of Educational Psychology, 94, 520-538.

Bereiter, C. (2002). Education and mind in the knowledge age. Mahwah, NJ: Lawrence Erlbaum.

Becker, B. E., \& Luthar, S. (2002). Social-emotional factors affecting achievement out- comes among disadvantaged students: Closing the achievement gap. Educational Psychologist, 37, 197-214.

Bransford, J. D., Vye, N. Y., Kinzer, C., \& Risko, V. J. (1990). Teaching thinking and content knowledge toward an integrated approach. In B. Jones (Ed.), Teaching thinking (pp. 381413). Hillsdale, NJ: Erlbaum.

Chan, C. K. K. (2013). Collaborative knowledge building: Towards a knowledge- creation perspective. In C. E. Hmelo-Silver, C. A. Chinn, C. K. K. Chan \& A. O'Donnell (Eds.), The International handbook of collaborative learning (pp. 437-461). New York: Routledge.

Deci, E. L. \& Ryan, R. (1992). The initiation and regulation of intrinsically motivated learning and achievement. In A. Boggiano \& T. Pittman (Eds.), Achievement and motivation (pp. 936). New Y ork: Cambridge University Press.

Eggen, P. D. \& Kauchak, D. P. (2003). Learning and Teaching: Research-Based Methods (4th ed.). Upper Saddle River, NJ: Pearson Education Inc.

Ellis, E.S., Worthington, L.A., \& Larkin, M.J. (1994). Executive summary of the research synthesis on effective teaching principles and the design of quality tools for educators. University of Oregon: National Center to Improve the Tools of Educators.

FNBE. (2014). National core curriculum for basic education 2014. Helsinki, Finland: Finnish National Board of Education. Available at: http://www.oph.fi/english/ curricula_and_qualifications/basic_education.

Haataja, E., Moreno-Esteva, E. G., Salonen, V., Laine, A., \& Toivanen, M., Hannula, M., S. (2019). Teacher's visual attention when scaffolding collaborative mathematical problem solving, Teaching and Teacher Education, 86, 102877.

Kirschner, P., \& Clark, R. E. (2006). Why Minimal Guidance During Instruction Does Not Work: An Analysis of the Failure of Constructivist, Discovery, Problem-Based, Experiential, and Inquiry- Based Teaching, Educational Psychologist, 41(2), 75-86. 
National Academy of Science, Engineering and Medicine. (2018). How people learn II: Learners, contexts, and cultures. Washington, DC: National Academies Press. doi: $10.17226 / 24783$

OECD. (2017). How does PISA measure students' ability to collaborate?. PISA in focus, No. 77. Paris, France: OECD Publishing. https://doi.org/10.1787/f21387f6-en.

Polya, G. (1957). How to solve it. Princeton, NJ: Lawrence Erlbaum.

Rosales, J., Vicente, S., Chamoso, J., Muñeza, D., \& Orrantia, J. (2012). Teacher-student interaction in joint word problem solving: The role of situational and mathematical knowledge in mainstream classrooms. Teaching and Teacher Education, 28(8), 1185e1195. https://doi.org/10.1016/j.tate.2012.07.007.

Sak, U., \& Eristi, B. (2012). Think Less - Talk More or Talk Less - Think More: A Comparison of Gifted Students' Engagement Behaviors in Regular and Gifted Science Classrooms. AsiaPacific Journal of Gifted and Talented Education, 4(1), 1-11.

Slavin, R. E. (1996). Research on cooperative learning and achievement: what we know, what we need to know. Contemp. Educ. Psychol., 21, 43-69.

Shrestha, P. (November 17, 2017). Overt vs Covert Behaviour. Psychestudy [Online]. Available at: https://www.psychestudy.com/behavioral/behavior/overt-vs-covert.

Snell, J., \& Lefstein, A. (2018). "Low ability," participation, and identity in dialogic pedagogy. American Educational Research Journal, 55, 40-78.

Stein, M. K., Engle, R. A., Smith, M. S., \& Hughes, E. K. (2008). Orchestrating productive mathematical discussions: Five practices for helping teachers move beyond show and tell. Mathematical Thinking and Learning, 10(4), 313e340. https://doi.org/10.1080/10986060802229675.

Törner, G., Schoenfeld, A. H., \& Reiss, K. M. (2007). Problem solving around the world: Summing up the state of the art. ZDM Mathematics Education, 39, 5-6. https://doi.org/10.1007/s11858-007-0053-0.

Trilling, B., \& Fadel, C. (2009). $21^{\text {st }}$ century skills: Learning for life in our times. San Francisco, CA: Jossey-Bass.

Yang, Y., Aalst, J., \& Chan, C. (2019). Dynamics of Reflective Assessment and Knowledge Building for Academically Low-Achieving Students, American Educational Research Journal, Vol. XX, No. X, pp. 1-49.

Van de Pol, J., Volman, M., \& Beishuizen, J. (2010). Scaffolding in teacher-student interaction: A decade of research. Educational Psychology Review, 22, 271e297. https://doi.org/10.1007/s10648-010-9127-6. 